\title{
ENERGY EFFICIENT BUILDING DESIGN
}

\section{A Transfer Guide for Local Governments}

\author{
Energy Task Force
}

of the Urban Consortium for Technology Initiatives

MONTGOMERY COUNTY, MARYLAND

Conducted by

Paul C. Tseng, P.E., Project Director

Ronald J. Baicn, P.E., Project Manager

Dale Stanton-Hoyle, Project Engineer

Capital Projects Management Division

Department of Facilities and Services

Montgomery County, Maryland 


\section{PREFACE}

\section{URBAN CONSORTIUM ENERGY TASK FORCE RESEARCH}

THE URBAN CONSORTIUM (UC) is a special network of the Nation's largest cities and urban counties brought together by PTI to find new solutions to their common concerns. The UC provides a creative forum where elected and appointed officials can identify, test, and validate practical ways to improve the provision of public services while generating new revenue opportunities. With staff, management, and business services provided by PTI, the UC addresses the critical needs of large local governments through its three task forces: Energy, Environment, and Telecommunications and Information.

The Urban Consortium Energy Task (UCETF) has 20 members and was established to imprive urban energy management and decision-making through applied research and teclinology transfer. The UCETF focuses on developing and sharing new approaches and in novative solutions to energy management problems with local governments. Projec:s are organized in thematic units and co- $m$ anaged by a member of the Task Force.

A description of the 1991 program Units and projects are:

\section{ALTERNATIVE VEHICLE FUELS AND TECHNOLOGIES (AVF)}

Alternative vehicle fueis offer a very strong potential to aid in the reduction of U.S. dependence on foreign oil supplies, with the resulting benefits of decreased air pollution in urban areas. Local governments can play an instrumental role in realizing this potential through practical applied research and highly visible demonstrations of alternative fuels and technologies. Issues addressed this year include identifying (a) intensive and credible market development efforts based on an applied research and de:monstration program that combines reliable technology with experience-tested applications, (b) environmental and energy diversity benefits, and (c) institutional and infrastructure barriers. The 1991 AVF unit consists of:
Broward County, FL -- Dual-Fuel Conversion Demonstration and Technology Transfer Project

New York City, NY .. Alternative Fuel Vehicle: Financing Issues

Denver, $\mathrm{CO}$... Technical and Market Comparison Between H2/CNG (Hythane), Electric Hybrid, and CNG Fueled Vehicles

Denver, CO -- An Alternative Fuels Floet Evaluation System -- A Transfer Project

Detroit, MI -- Analysis of Institutional and International Limitations for Alternative Fuel Vehicles

Washington, DC -- Comparison of Energy Consumption, Energy Savings, and Environmental Effects of EVIPV vs. Conventional Gasoline Vehicle

\section{ELECTRICITY MANAGEMENT}

Urban interests for electricity management focus on means to maintain stable, secure and reasonably priced supplies of electric energy. Approaches include procedures for better demand management, application of "least cost" planning concepts, appropriate use of decentralized and/or small power production facilities, improved end-use efficiency, and developing sound structures for cooperative action among municipalities and energy utilities. Urban strategies include support for decentralized "small" power production, along with better demand management and improved end-use energy efficiency. The successful development and implementation of such strategies will require close cooperation with the utility industry and will address topics in areas of institutional relations, source flexibility, and demand-side management. The 1991 Electricity Management Unit consists of:

Albuquerque, NM -. Alternatives to Traditional Rate Setting

Chicago, IL .. Integrating Innovative Supply and Efficiency Techniques

Chicago, IL -- The Chicago Energy Management Cooperative

Dade County, FL -. Energy Cost Reduction Through Resource Recovery 
Detroit, MI .- Hydraulic Waste Energy Recovery (Phase II) City of Detroit Water Distribution System

San Jose, CA -- Utility/Local Government Partnership to Increase Energy Conservation in New Construction

\section{ENERGY EFFICIENT FACILITIES}

Activities involving energy efficient facilities are at present, part of a national effort to achieve maximum cost-effective energy productivity in the building sector. There exists a need for collaboration between local government officials responsible for energy and environmental programs and other local government officials responsible for facilities, as well as the Federal officials and private sector groups, e.g. utilities. New technologies and management/administration practices to advance energy efficiency in facilities require major partnership efforts and transfer programs. Multi-family housing that has a large concentration of low-income families presents a unique challenge to lowering energy costs and maintaining energy efficient facilities. Projects in this unit are:

Boston, MA -- Neighborhood Energy Efficiency Outreach Partnership

Columbus, $\mathrm{OH}$.- Energy Efficiency and Indoor Air Quality: Solutions for Fire Stations

Louisville, KY .- Partnership Approach to Energy Efficiency in Non-Profit Facilities

Montgomery County, MD .- Technology Transfer of Building Energy Design Guidelines

New Orleans, LA -- Residential Utility Costs Comparative Study

Phoenix, AZ -- Variable Frequency Drive Applications Guide

Portland, OR .- Energy Savings Through Operation and Maintenance Training in the Low-Income Multi-Family Sector

Washington, DC .. Comparison of Two Techniques for Identifying Energy Conservation Measures in Low Income Homes

\section{ENERGY, ENVIRONMENT and ECONOMIC DEVELOPMENT}

This an area that has both visionary and immediate practical emphases on the definition and evaluation of realistic strategies and actions to support energy-sustainable and environmentally responsible communities. Emphases include uses for renewable energy, practical domestic supply and conservation alternatives, and the synthesis of energy concerns with wider local government interests in economic development, environmental quality, and internal cost control. Urban strategies to improve energysustainability require attention to both broad based institutional changes, as well as specific projects designed to encourage the application of appropriate technology and community development practices. The "Sustainable Communities" project has involved three municipalities with State agency, Lawrence Berkeley National Latoratory, and a formal advisory committee with broad national representation. Projects under this unit are:

Austin, TX -- Energy Star Sustainable Rating Program

Phoenix, AZ .. Impact of Heat Island on Cooling and Environment: A Demonstration Project

Pima County, AZ -- Tucson Solar Village - Project Management

Portland, OR -- Sustainable City Transfer Project

San Francisco, CA -- Neighborhood Energy/Economic Development at South Bayshore

San Francisco, CA -- Sustainable City Transfer Project

San Jose, CA -- Sustainable City Transfer Project

Seattle, WA -- Coordination of Energy and Air Quality (CEAM)

Seattle, WA -- Bicycle Program -- Urban Trails System

Tucson, AZ -. Local Government Involvement in Long Term Resource Planning for Community Energy Services

Reports from each of these research projects, including this report, are specifically designed to aid the transfer of proven experience to other local governments. Readers interested in obtaining any additional reports or further information about the Urban Consortium Energy Task Force and the Urban Consorium should contact:

Energy R\&D Prográm

Public Technology, Inc.

1301 Pennsylvania Avenue, NW

Washington, DC $200 C 4$

$1-800-852-4934$ 


\section{Acknowledgements}

The Project Manager was Ronald J. Balon, P.E., Senior Energy Engineer with the Montgomery County Department of Facilities and Services. Mr. Balon conducted the technical research, performed life-cycle-cost analyses of energy technologies, prepared energy guideline materials and implemented coordination requirements for energy efficient design of new and renovated County buildings. In addition, Mr. Balon prepared training and presentation materials, along with this comprehensive final report.

The Project Director was Paul C. Tseng, P.E., Chief Engineer with the Montgomery County Department of Facilities and Services. Mr. Tseng provided overall project direction and management support for implementation of energy design guidelines for County factlities.

The Project Engineer was Dale Stanton-Hoyle, Energy Engineer with the Montgomery County Department of Facilities and Services. Mr. Stanton-Hoyle provided research and editorial assistance and presented parts of the transfer seminar.

Peer review of these guidelines was provided by Mark Isaacs of Isaacs Waldron Architects, Louisville KY, and W. Dwight Bailey, City Planner with the City of Chicago Department of Planning, and Joseph A. Ventresca, Energy Coordinator for the City of Columbus, Ohio.

Special thanks go to the Department of Energy for providing the grant which made this project possible. Special thanks for technical assistance go to Unit Managers Dr. Anthony Laska and Christopher Ward. 


\section{Contents}

\section{Page}

CHAPTER 1 - OVERVIEW

Abstract ................... 1

Project Purpose. . . . . . . . . . . . . 3

Report Organization. . . . . . . . . . . 4

CHAPTER 2 - BACKGROUND

Introduction ................. . . 7

Building Design Process. . . . . . . . . . . 9

Types of Energy Requirements . . . . . . . . . 11

Energy Dasign Guidelines............ . 19

CHAPTER 3 - PRJDUCTS TO ASSIST TRANSFER

Introduction ................ . . 21

Re-Packaged Energy Design Guidelines......... 21

Videotape ................. 22

CHAPTER 4 - TRANSFER TEST CASES

Introduction . . . . . . . . . . . . . 25

Technical Training . . . . . . . . . . . 25

Results ................... 27

CHAPTER 5 - CONCLUSIONS

Lessons Learned . . . . . . . . . . . . . . . 29

Suggestions for Application . . . . . . . . . 30

Future Directions . . . . . . . . . . . . . 33 


\section{Chapter 1 - Overview}

ABSTRACT

The aim of the project was to transfer Energy Design Guidelines previously developed by the Montgomery County Department of Facilities and Services, to other independent County agencies, including the public schools, community college system, and park and planning commission.

Montgomery County enacted a regulations for energy efficient design of buildings in July 1986. In essence, the regulation sets energy consumption limits for buildings and mandates life-cycle-cost analys is of design choices. This regulation gave the Department of Facilities and Services broad responsibility for implementing energy efficiency in its new and renovated facilities:

"An architect / engineer must design County facilities to meet or exceed the Energy Performance Index issued for the facility... The building designer is required to provide a Life-Cycle-Cost Analysis and the County will determine which component alternatives are to be evaluated by the designer."

In 1987 Montgomery County received an Urban Consortium grant to build the organizational and technical means to realistically carry out the "simple" directives of the regulation. The results of that effort have been highly successful and beneficial to the county. In fact, application of these guideliries over the last several years have reduced new building energy consumption in Montgomery County buildings by 30 to 50 percent and without an increase in the first-cost of construction.

The current transfer grant produced the following major accomplishments and products: 
- Energy Design Guidelines and design contracts were repackaged for a wider audience of energy managers in local government. The Guidelines received peer review by other jurisdictions to ensure adaptability. The Urban Consortium makes the Guidelines available as a publication for a nominal charge.

- A series of seminars on individual technical topics were developed and presented in 7 segments at monthly meeting of an Inter-agency committee on energy and utility management (I.C.E.U.M.). Engineers with the Department of Facilities and Services (DFS) also presented a final oneday seminar on controlling the design process for new buildings to follow energy design guidelines.

- Agencies outside of DFS began using the Guidelines on their new capital projects. All agencies reported success incorporating design processes and new standards and technologies into new projects. The I.C.E.U.M. committee formally adopted the Guidelines as a model for government agencies to follow.

- For jurisdictions outside Montgomery County, a yideotape provides a "sales pitch" for using the Energy Design Guidelines. The presentation aims at capturing upper management interest and support for the idea by emphasizing practical, bottom-line points. In fact, highly efficient buildings can be built at no added first cost compared to conventional construction. The Urban Consortium makes available copies of this tape entitled "Energy-Efficient Building Design - More Thinking, Not More Money."

The key "Lessons Learned" on the project are as follows:

- Other jurisdictions can readily adopt Energy Design Guidelines and produce significantly better buildings without increasing construction costs. 
- For best results, adopt the design process in its entirety before the start of a new project. A smooth design process depends on selecting a design team with appropriate expertise and using a design contract with all provisions needed to implement the technical Guidelines.

- Successful implementation of the Guidelines requires training of inhouse personnel for project management and tecknical reviews. This requirerent is not a major obstacle if the agency has existing staff with prcfessional architectural or engineering background. Over the course of this project, training time totalled only three days.

- An economic analysis indicates a very high rate of return in utility savings compared to the cost of implementing the program.

This development and transfer effort was conducted entirely by County engineering and energy staff. Peer review was obtained from other Consortium jurisdictions on energy review processes and design guidelines.

PROJECT PURPOSE

The overall goal of the project was to promote transfer of Energy Design Guidelines for Local Government Buildings previously developed by Montgomery County. The work plan included the following major objectives:

- Reformat the Guidelines for a wider audience: Remove references specific to Montgomery County. Produce a more user-friendly document with illustrations and greater explanation of technologies and design approaches.

- Provide design management guidance: Develop a "flow chart" to describe steps in design management to implement the Energy Design Guidelines.

- Peer Review: Have the resulting documents reviewed by other jurisdictions to identify any weaknesses that would hinder transfer. 
- Test transfer to other agencies of County government: Train other agencies and assist initial use of the Guidelines. Training to include:

5 monthly technical seminars ( 1.5 hours each)

1 day seminar emphasizing design management

- Produce a video to assist transfer: To obtain top level support for advanced energy design in government buildings. A brief promotional video to highlight the advantages of using Guidelines and to suggest the initial steps to implementing a program.

REPORT ORGANIZATION

This report is comprised of five chapters and five appendices. The major sections are organized as follows:

Chapter 1 -.

provides an abstract and overview of the document and report organization.

Chapter 2 -.

introduces the fundamental concepts of the building design process, energy codes and standards and energy budgets. Introduces results of the Year 9 research effort cumbining the above tools into Energy Design Guidelines and design contract requirements. Describes the research plan for testing transferability to other jurisdictions.

Chapter 3 -.

describes the development of products for transfer; a repackaging of the Guidelines for a national audience and a videotape for selling the concept to goverument executives. 


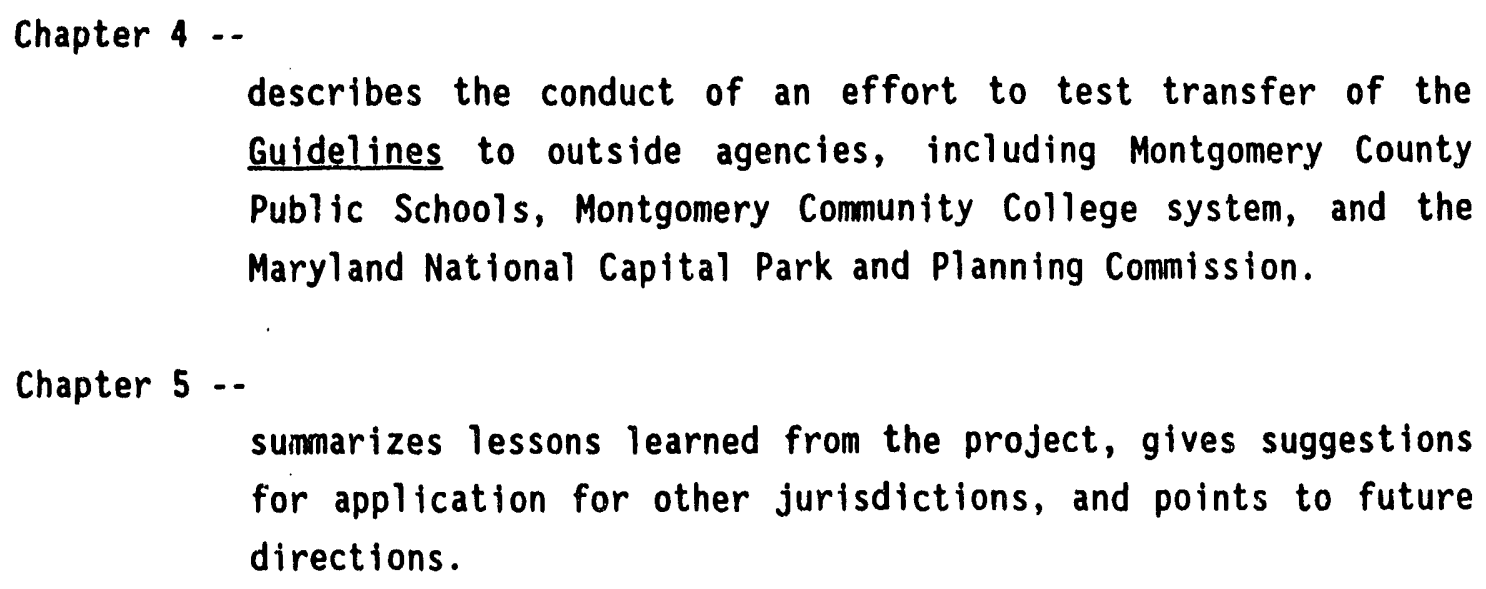




\title{
Chapter 2 - Background
}

\author{
INTRODUCTION
}

\section{Energy Conservation in Montgomery county}

The energy price shocks and shortages of the 1970's first raised concerns over energy use in Montgomery County Government facilities. County officials and citizens' groups recognized the need for County Government to reduce its energy expenditures and set a positive conservation example for the public. As a result, Montgomery County legislated an innovative, government-wide energy conservation program. Like many other jurisdictions, the Montgomery County energy program included funds for an energy retrofit program in County facilities. The unique aspect of the Montgomery County program was that it also directly addressed the process of new construction and major renovation of County facilities. New construction is the "other side of the energy coin" where lies the larger, and largely untapped, potential for energy conservation in government facilities.

County energy legislation covered each major branch of County government: Public Schools, Community Colleges, Water and Transportation Departments, as well as general government facilities. The general government facilities includes offices, community centers, libraries, police and fire stations. These General Government facilities are designed and maintained under the Department of Facilities and Services (DFS) in the executive branch of County Government. DFS includes engineering and architectural design management (housed in Capital Projects Management) alongside Maintenance and General Services functions. The design management functions include full review of all designs for new construction and major renovation by energy personnel. 
Management Structure and Partners

A project team was formed within DFS to carry out the transfer work. Participants were Ronald J. Balon, P.E., Senior Energy Engineer, Paul C. Tseng, P.E., Chief of Engineering Services, and Dale Stanton-Hoyle, Energy Engineer. This project team performed the developmental work on the Guidelines, and the training of other agency personnel. Partners in the project were included from several other County agencies as follow:

Montgomery Community College - Mike Whitcomb, P.E.

Park and Planning Commission - Jan Wilson, Architect

Montgomery County Public Schools - Sean Gallagher, P.E., Ray Marhamati

Partners received training and implemented the Guidelines in their respective agencies.

\section{Capital Improvement Projects}

Capital Improvement Projects (C.I.P.) are projects funded by the County to build or perform major renovations to its facilities for serving the public. The County retains consultants to design the buildings but reviews and manages the design through the County architects and engineers in Capital Project Management Division. In any given year, the County completes between $\$ 15,000,000$ and $\$ 30,000,000$ of C.I.P. design work. The complete, on-going project 1 ist totals around $\$ 100,000,000$.

Ideally, energy conservation needs are incorporated in the program for a C.I.P project from the outset and money for energy improvements is budgeted along with money for all other program items. In this way there is no fixed amount of money each year for energy conservation - each project is on its own. There is a separate C.I.P. of approximately $\$ 600,000$ per year for small energy retrofit projects to be used for building outside of major renovations. These energy retrofit projects are managed separately from other C.I.P. projects.

\section{Legislation for Building Energy Design Standards}

In 1985 the County Council passed legislation setting energy design standards for all C.I.P. projects conducted by the County.

* Energy Budgets: Building designs must meet energy budgets established by the State of Maryland or by DFS for given functions; office, library, community center, etc. Contracts for 
design signed after 1985 must include this energy budget requirement.

* Life-Cycle-Cost Analysis: Selection of energy systems and thermal envelope design shall be by 1 ife-cycle-cost analysis including future utility costs over a 20 year period.

* Options to be Analyzed: Options for analysis and inclusion in the project shall be determined by DFS.

\section{BUILDING DESIGN PROCESS}

In order to intervene successfully in the design of a facility, one must have a grasp of the complete process from initial assessment of needs to building construction. In Montgomery County, this process may extend from 2 to 6 years depending on the size and complexity of the project. However, each project follows distinct phases as described below. While these descriptions are specific to Montgomery County procedures and regulations, other jurisdictions should be able to identify similar or analogous steps in their own building process.

\section{Planning and Program of Requirements}

At the earliest phase of facility design DFS planners draw up a basic list of needs the facility would have to accommodate. For example, population growth may stimulate the need for a new library to serve 20,000 new patrons per year. These needs are then translated into specific building requirements or a "Program of Requirements"; the new library will need so many square feet of floor area, so many volumes of books, so much meeting and office space, and so on. Often a consulting firm will be retained to study the projected needs, provide a preitiminary Program of Requirements and a corresponding rost estimate.

If the need is established then the project will be submitted to the office of Management and Budget for funding. The project then becomes a "Capital Improvement Project" with a funding schedule spanning 2 to 6 years. The funding level at this point is normally corsidered fixed except for inflationary increases or major program changes determined by the county Execuitive. 
Selecting the Design Team

Once the need for a facility has been established, DFS issues a Request for Proposals (RFP) for comprehensive design services. Architectural and Engineering design firms prepare proposals describing their personnel and capabilities. DFS then evaluates the firms through their written responses and supplemental interviews. Criteria for evaluation include experience with similar projects, sufficient staffing to handle the work load, knowledge of local codes, and energy conservation design expertise. The design team with the highest overall score is generally selected for the project.

\section{Schematic Design}

The first phase of actual design work is designated "Schematic Design". Typical elements of Schematic Design work are a concept of the overall shape, style and orientation of the building, a layout of the floor space for the program, selection of an HVAC system type, and rough sizing of mechanical and electrical equipment. Schematic Desigr usually constitutes about 10 percent of the total design effort.

\section{Design Development}

The Design Development phase expands on the Schematic Design selections to provide more detail on the proposed building systems and construction. The Architect shows the intended direction of final design without yet carrying out the design, for the purpose of obtaining comments and further direction from the owner. Typical elements of Design Development are building elevations, detailed floor space layouts, building materials description, outline of specifications, location of mechanical equipment and utilities, single-line (preliminary) layout of ductwork and air-handling equipment, and reflected ceiling plans (lighting fixture placement). Design Development usually constitutes about 30 percent of the total design effort.

\section{Construction Documents}

Construction Documents constitute the final design level. These documents are used to obtain bids on the project by contractors and to direct the construction effort. The Construction Documents include all needed details to specify the building structure, materials, systems and quality of workmanship. Construction Documents constitute 100 percent completion of the design phase of the project. 


\section{Construction Afministration}

In Construction Administration the architect advises the owner and contractor on actual construction of the building. Typical Construction Administration elements are interpretation of Contract Documents, review of submittals from the contractor for compliance with contract drawings and specifications, physical inspection 0 ? the work, approval of progress payments, and final review for project acceptance.

\section{Post-Construction Services}

On larger or more complex projects, the Architect may follow through the first year of building occupancy to provide services such as HVAC commissioning, maintenance training, as-built drawings and warranty reviews.

\section{TYPES OF ENERGY REQUIREMENTS}

The above outline of the building design process suggests that the process of planning and designing a building can be long and complex. Energy considerations can enter at various points in this process and can take several different forms. For the building owner, there are five primary tools for influencing the design process:

* Energy Budgets - Maximum annual energy consumption set by the building owner, to be demonstrated by energy analysis by the designer.

* Life-Cycle-Cost Analysis - Selection of energy systems for the building by analysis of total costs over the lifetime of the equipment. Reliable life-cycle costing requires an energy analysis of the total building.

* Guide Specifications - Standard selections and specifications of the owner for use in all building designs.

* Public standards - Voluntary design criteria established by professional groups and organizations.

* Building Codes - Design requirements set by state and local governments as part of the building permit process. 
Each of these tools and their interrelationships are described below.

\section{Energy Budgets}

An energy budget is a total amount of energy a building will be designed to use during a year, adding together all sources of energy supplied to the building (electricity, natural gas, fuel oil, etc.) in common units of Btu's. This number may also be called an "energy target" or "building energy performance standard". In the case of the Montgomery County legislation it is referred to as an "Energy Performance Index" (EPI). The energy budget is usually normalized against the interior square footage of the buiding so the typical units of a budget will be "Btu's per square foot per year" $(\mathrm{Btu} / \mathrm{ft2} / \mathrm{yr})$. The details of the budget definition will vary from one source to another so that one must be careful to "compare apples to apples" when making comparisons.

Application. Compliance with an energy budget may be mandatory if the owner so requires, or it may be only a guide post against which to compare the design. Following our background survey, we found no jurisdiction, either federal state or local, which requires fixed energy budgets for all buildings as part of the permitting process. Thus, at the present time, the individual owner may set an energy budget if one is desired. Among government owners we were able to find only two who use fixed energy budgets for their own new buildings: the State of Maryland and Montgomery County, Maryland. The Federal Government has a program to develop energy budgets for its new buildings but implementation will not begin until 1992.

Setting Energy Budgets. Energy Budgets are generally set according to the function of the building. For example, an "Office Building" may have a budget of $42 \mathrm{kBtu} / \mathrm{ft2} /$ year while a "Library" may be set at $52 \mathrm{kBtu} / \mathrm{ft2} /$ year. The most well known source for such budgets is the federal Building Energy Performance Standards (BEPS). At one time BEPS were proposed as a national requirement for building design, however, the legislation was never enacted.

Multi-function buildings pose a problem to application of energy budgets since no single functional category will fit. For example, Montgomery County has several buildings incorporating social services, a library, daycare, and health services in one facility. Our approach has been to form a composite energy budget by averaging the various individual budgets, weighted by square footage for each function. The technical validity of this approach has not been established, but the federal 
government is researching the approach for use in its future program of energy budgets.

An alternative approach to using fixed budgets is to allow the designer to define an appropriate budget on a case-by-case hasis. A budget is determined by simulating a base-case building with comprehensive prescriptive energy standards (such as ASHRAE Standard 90.1-1989 or California Title 24) as a reference. The actual building may be of any design so long as it meets the equivalent energy budget set in this manner. The state of California allows this approach for all construction as part of the State building code.

Limitations. Use of energy budgets has been limited primarlly by the diversity of building functions. No two buildings are really identical in all functional respects, so it is difficult to lump them into fixed categories. At best, energy budgets can be realistically applied by an individual owrer dealing with a narrow range of building types with a good historical database of energy use. In Montgomery County experience, energy budgets can be applied to government building types. Careful attention must be paid, however, to establishing budgets.

A second drawback of energy budgets lies in the technical complexity of the analysis for commercial buildings. Sophisticated computer programs are generally necessary to obtain meaningful answers. The owner must be prepared to set up in detail the standard parameters to be used in the simulations and to check the consultant's input. Many consultants are not adept at energy analysis and may imbed large errors in the input.

Benefits. Despite its limitations, an energy budget can be a useful tool. When used properly, the budget focuses attention on basic energy concerns at an early point in the design process. Budgets can lead to significantly better designs and lower energy consumption than simpler approaches discussed below. Moreover, an energy budget can protect the owner from future energy price shocks. Relative prices of fuels may fluctuate drastically or utility rate structures can change so as to invalidate a life-cycle-cost analysis a few years down the road. If the lilding meets a conservative, overall energy budget, the owner is better protected from price shocks.

\section{Life-Cycle-Cost Analysis}

Life-Cycle-Cost Analysis refers to the selection of options by lowest overall cost to the ovner and considers future utility costs and maintenance costs in 
addition to initial "first costs". Life-Cycle Costing uses economic factors to properly weight the cost of future utility outlays and bring energy costs into the decision-making process. A Life-Cycle-Cost approach thus provides a considerable boost to energy conservation over a standard approach emphasizing first costs only.

Application. Life-Cycle Costing is most frequently used in building design to select between alternative Heating, Ventilating and Air-conditioning (HVAC) system options. It is considered good practice (see ASHRAE Standard 90.1-1989) to analyze at least three potential system types, for example, hydronic heat pumps, Variable air Volume, and constant volume, for any given building. Options in central plant equipment should also be analyzed in logical combination with the HVAC system types. Exampies of options in plant equipment might be rooftop units, central chiller or thermal energy storage. Life-Cycle costing is also frequently applied to lighting selections. The analysis can be used to trade off higher fixture costs against lower operating and air-conditioning costs. Life-cycle analysis may also be applied to architectural features such as glazing selection, daylighting, and building orientation.

Although life-cycle-cost analys is is sometimes applied to individual, isolated building energy systems, it is best when the building and its systems are analyzed as a whole. In other words, a comprehensive simulation should be performed addressing the lighting, HVAC options and architectural features together, and the interactions among these elements. Two factors require the combined analysis:

* The interaction of energy systems in a commercial building are complex and trying to study one system in isolation often leads to significant errors in energy calculations. For example, skylights and lighting controls may greatly reduce lighting energy consumption in a building, but the apparent savings may be negated by increased heating and cooling loads for the HVAC equipment.

* Significant economic trade-offs may be made between systems which are not apparent when systems are viewed separately. For example, selecting a higher-efficiency lighting system may appear to cost more than a standard lighting system in isolation, but may actually be lower in net first cost when reduced 
af $r$-conditioning size and first cost are included in the anilysis.

Limitations. Life-cycle cost analys is requires complex energy analys is similar to that required by the energy budget approach. The owner must be ready to define carefully the economic parameters and analysis methods and to review the work of the consultant for conformance.

Benefits. Codes and standards lag current technology by several years due to the nature of the code preparation and adoption process. Life-cycle cost analysis allows the owner to consider the latest techrologies to find the most econcmical system available right now for a given project. The difference can be significant and well worth the additional analysis effort. In general, the bulk of the cost of a building lies in operating costs over its life cycle. The cost of design and analysis is minor compared to the eventual operating cost of the building.

\section{Guide Specifications}

When a project goes out for bid, it includes a book of specifications describing each material and piece of equipment to be used on the job. The owner can use this specification to control the energy efficiency of the building. For example, the owner can specify high-efficiency lighting fixtures, lamps and ballasts selected by previous life-cycle cost analysis. The most direct way for the owner to achieve this control is to provide standardized or guide specifications to the designer at the outset of the project. Typical areas where standardized specifications make sense include lighting, energy management and control systems, variable frequency drives, and boiler type and efficiency. Wherever a standard set of selections or performance criteria can be established, a guide specification can be prepared. The benefit of this tool lies in removing reliance on individual designers to consider and develop energy-related specifications for each individual job. Having a guide specification helps to avoid misunderstandings and iterations between the designer and the design reviewer or owner.

\section{Public Standards}

Professional groups interested in energy conservation develop and maintain standards of design for voluntary use by the public. The American Society of 
Heating, Refrigerating and Air-conditioning Engineers (ASHRAE) cruatod the landmark public energy standard in 1975, namely ASHRAE Standard 90 "Energy Conservation in New Bullding Design". The standard provides a prescriptive or "do it this way" approach to energy conservation as opposed to the energy analysis approach required by energy budgets or life-cycle cost analysis. For example, the standard states minimum R-Values of insulation, minimum equipment efficiencies and HVAC system control requirements for the designer to use. It enjoys a very broad consensus across the design professions as the basis of good current practice - good, but not optimal - in its efforts to reduce building energy use.

The New Standard 90. Since 1975, much research has been done on commercial building energy conservation and much has been learned. Standard 90 has been recast in light of current knowledge and designated as Standard 90.1-1989. The new version makes significant improvements over the initial version with these key features:

* Climate Sensitive: The 1975 version of Standard 90 had the stigma of being a "northern climate standard" in its insulation requirements. The new Standard matches thermal envelope requirements to specific climates for a large number of listed cities. Also, the wall and roof insulation levels are typically twice as high as the previous Standard, in recognition of generally increased energy costs since 1975.

* Sets Lighting Wattage Budgets: The new Siandard fixes maximum lighting wattage budgets for facility functions. This step recognizes the driving influence of lighting in commercial building energy use.

* Limits Window Area: The new Standard establishes a maximum percentage of window area to be allowed in building walls on a case-by-case basis, given input on the climate, glass performance factors, internal heat gains in the building, and window overhangs. A sample selection table appears in Figure 4. This approach is more scientific and produces better energy designs than the previous Overall Thermal Transmittance Value (OTTV) approach.

* Improved Controls: Appropriate control for HVAC system equipment is updated and more detailed. Daylighting controls for 
fluorescent fixtures are promoted, along with occupancy sensors and multilevel switching capability.

In all, the revised Standard provides a much more comprehensive and technically sound basis for energy conservation design.

Application. Parts of the earlier Standard 90-75 (or 90A-1980, the last official update) have been incorpcrated into building codes of the majority of states. Nevertheless, many buifings are constructed each year that do not meet standard 90, even in its 1975 version. This is because most building codes make use of only parts of the Standard and even these sections may be considerably "watered down" to simplify plan checks. The one notable exception is the State of California which has a building code (Title 24) very similar to the latest Standard 90.1-1989. The building owner wishing to apply Standard 90 at its best should become familiar with the latest proposed version of the Standard and work with the designer to achieve specific compliance.

Limitations. The prescriptive standard may be viewed as a safety net on design for items which can be easily checked. It does not optimize a design or select specific technologies for use as do energy analysis and life-cycle-cost analysis.

Benefits. The prescriptive standard does address each critical area of building energy use and provides a starting point for the designer to work from in base case design and energy analysis.

\section{Building Codes}

Agencies of local, state and federal government write regulations to implement standards and codes. Codes are specific enforceable criteria for constructing buildings anc installing systems and subsystems such as HVAC systems. Energy code criteria typically include minimum equipment efficiencies, ventilation rates, and overall thermal transmittance value of the building shell. The quality of energy codes and enforcement varies greatly from one jurisdiction to another. There are literally hundreds of energy code jurisdictions in the United States.

Application. Building codes apply to all construction taking place within the jurisdiction covered. Generally speaking, it is necessary to show 
design compliance with the local code to obtain a building permit. The level of actual enforcement of codes may vary significantly from one jurisdiction to another.

Limitations. Building codes are limited by the personnel available to review plans and make inspections. Accordingly, most codes address only minimal energy qualifications which can be easily checked, such as equipment efficiencies and insulations levels. Codes also tend to be limited by the time required to reach consensus on new energy criteria and legislative review schedules. This problem is discussed further in the next section, Combining Tools.

Benefits. The benefit of an energy code is that it applies to all buildings. Designers soon standardize on details and specifications that meet code. If the local energy code is strong and up to date, it can make a solid starting pcint for energy-efficient building construction. If on the other hand, the local code is weak and out-of-.date, it can be a hindrance to design. The building owner should carefulily evaluate local energy code requirements and then use the supplemental tools described above as appropriate.

\section{Combining Tools}

All of the above tools are interrelated and generally not used in isolation. For example, a project using the "Energy Budget" tool will likely make use of each of the four other tools as well at various points in the design; Life-Cycle-Costing may be used to select the HVAC system type, Guide Specifications may determine the lighting lamp and ballast types, Standards may determine the insulation levels and Building Codes the ventilation rates. The owner must be thoroughly familiar with each of the tools to be used so as to avoid unnecessary duplication or contradiction of design criteria.

There exists also a "migration" from one tool to another over time which further defines the relationship between tools. New technologies and energy cost shocks are first recognized by Energy Budgets and Life-Cycle-Cost Analysis. For example, a sudden steep increase in the price of fossil fuels may make it cost-effective to double the level of roof insulation in a new building over minimum code requirements. Over time, the results of repeated energy and cost analyses make their way into standards and Guide Specifications. To continue the example, the need for increased roof insulation could be adopted in the next revision of a public standard such as 
ASHRAE Standard 90. Next, the new recommendation may be adopted in national building codes such as the Building Officials and Code Administrators (BOCA) National Energy Conservation Code. Finally, the National Code may be adopted into local building codes where it is applied to all new buildings.

This migration of information is useful but can be very slow. Based on our investigation of the process followed in Montgomery County and several other jurisdictions, the typical time lags would be as follows:

Recognition by Life-Cycle-Cosi Analys is (immediate)

Recommendation in Public Standards (5 - 10 years)

Adoption in National Building Code (3 years)

Adoption in local condes (2 years)

In total, it typically takes 10 to 15 years for information about cost-effective energy-conservation measures to become established in local codes where it will be applied to all buildings. Therefore, there is much to be gained from use of anticipatory tools such as energy analysis and life-cycle-cost analysis, especially at a time when technology and/or energy prices are changing rapidly.

ENERGY DESIGN GUIDELINES

Montgomery County developed and successfully applied a system of Energy Design Guidelines for its buildings as a result of Urban Consortium Year 9 grant funding. These comprehensive guidelines combine all the above tools for achieving energy-efficiency in new buildings in a way that makes sense for a local government. Application of these guidelines over the last several years have reduced new building energy consumption in Montgomery County buildings by 30 to 50 percent and without an increase in the firstcost of construction. Ancillary products to the Guidelines include design contract provisions, rating criteria to use in selecting designers, and report formats for mandatory energy reports at different design phases. The development of these guidelines is detailed in our Year 9 Final Report "Energy-Efficient Building Design - Guidelines for Local Government", document D9/88-303, 11/89-100, published by Public Technology Incorporated. 
The reader should review a copy of the Year 9 report for more detailed information about the guidelines development. The Year 12 transfer project seeks to inake the results and products of this previous grant available to a wider audience by actively promoting technology transfer to other jurisdictions. 
Chapter 3 - Products to Assist Transfer

INTRODUCTION

Two products were developed to assist transfer of Energy Design Guidelines to other jurisdictions. One was a re-packaging of the Guidelines document to improve its accessibility and instruct those less acquainted with its use. The other was a video tool to help energy managers sell the concept of efficient building design to government executives who could "get the ball rolling" in new building designs. This chapter describes the enhancements and developments resulting from these efforts.

RE-PACKAGED ENERGY DESIGN GUIDELINES

The existing package of Energy Design Guidelines was extensively upgraded to assist transferability. Many of the recommendations for changes were the result of peer review. Peer review of these guidelines was provided by Mark Isaacs of Isaacs Waldron Architects, Louisville KY, and W. Dwight Bailey, City Planner with the City of Chicago Department of Planning, and Joseph $A$. Ventresca, Energy Coordinator for the City of Columbus, Ohio. Key changes were made to the Energy Design Guidelines to enhance their use by other jurisdictions as described in this section.

\section{Structuring of Guidebook}

Several changes were made that other jurisdictions should be aware of:

- The Gutdelines were reproduced in 3-ring binders instead of bound. This step permits designers to easily pull-out and circulate or reproduce sections for the different design disciplines or subconsultants. It also permits the government energy manager to easily augment or change material in the Guidelines. Changes are frequently 
made in a document close to the state of the art in energy technologies.

- The Guidelines were enhanced to be more of a training document. The Guidelines were placed in double-column format with the left column reserved for diagrams, figures, lllustrations and text boxes illustrating important points in the text. This step makes the guidelines more visualiy oriented and assists learning the material.

\section{Overview Section Added}

A extensive new overview section was added to orient designers to the guidelines and the design control process that will be used on the project. All players in the design process, on the government side as well as the design side, will want to review this section at the start of each project. The overview includes:

- An enhanced, detailed flow chart of activities at each phase of design.

- An enhanced "Technology Application Matrix" summarizing standards by building size.

- Process descriptions and "Ground Rules" for energy-efficient building design.

Copies of Energy Design Guidelines are available from the Urban Consortium or directly from Montgomery County for a nominal charge. An electronic copy of text portions of the Guidelines may also be purchased to assist adaption to your jurisdiction.

\section{VIDEOTAPE}

At unit meetings of this transfer grant, several other jurisdictions expressed frustration with being outside the design process for their own buildings and not being able to establish a design guideline or review program. To help overcome the barriers faced by other jurisdiction, Montgomery County produced a videotape to sell the concept of energy design 
guidelines to government executives. The main objectives of the video are to communicate the following points:

- Using Energy Guidel ines does not increase project first-cost.

- Quality, Comfort and Efficiency go together.

- Energy and Utility savings of 30 to 50 percent are achievable.

The tape includes interviews with the County Executive of Monisomery County, as well as the President of the County Council and Energy Planner, each attesiting to the advantages of the design guidelines. The 8-minute tape entitled "Energy-Efficient Building Design - More Thinking, Not More Money" is available from the Uyban Consortium or directly from Montgomery County for a nominal charge. Tha tape was produced by the project team members using professional video training and equipment available to the community from Montgomery Community Tele': is sil. 


\section{Chapter 4 - Transfer Test Cases}

INTRODUCTION

To test transferability of the Guidelines, DFS enlisted the cooperation of three other major county agencies; the Montgomery County Public Schools, Montgomery Community College System, and the Maryland-National Capital Park and $\mathrm{Planning}$ Commission. These groups already met monthly under auspices of the Inter-Agency Committee on Energy and Utility Management (I.C.E.U.M.). The three agencies agreed to receive training and begin using the Guidelines on new building designs for their facilities.

TECHNICAL TRAINING

The Project Manager, Ron Balon P.E., prepared and presented five training sessions of about $11 / 2$ hours each to the group on the following topics:

Lighting Design

Thermal Envelope Design and Energy Budgets

Efficient HVAC Equipment and Systems Criteria

Indoor Air Quality

Commissioning Mechanical and Electrical Systems

Each training session was held at a different DF's facility demonstrative of the subject matter. The session on Lighting Design was held at a new residential care facility built with parabolic electronic/T8 fluorescent fixtures and PL downlights. The installation meets all recommended light levels with only 0.9 Watt per square foot of connected lighting load, 70 
percent less than normal design practice. The session on Thermal Envelope was held at the Damascus Library and Community Center. Daylighting provides 75 footcandles of illumination throughout most of this building through a system of roof monitors. The session on HVAC systems was heid at the UpCounty Government Center. This Center features a low-temperature airconditioning system supplied from an ice harvester thermal storage system built into the foundation. In its first year of operation this building received three times the anticipated number of client visits and still used 40 percent less energy than any comparable county facility. Each of the facilities was constructed at or below conventional construction costs. Each training session was followed by a tour of the facility and discussion of operations.

A final, full-day seminar was held at the UpCounty Government Center to present design management techniques. In addition to the I.C.E.U.M. members, the seminar received representatives from Public Technology, Incorporated, the U.S. D.O.E., and the Maryland Energy Administration. The project team presented material in the following areas:

- Overview of the technical Guidelines, emphasizing improvements over BOCA energy code and ASHRAE 90.1-1989.

- Cost containment, addressing the myth of increased first cost from using energy guidelines.

- Design management, presenting the flow chart to successfully reviewing and controlling the work of consultants.

- Simulated Pre-Design meeting between consultants and government managers and energy engineers. Audience participation on an actual community center design.

- Facility tour and discussion of operations.

The technical training sessions and management seminar can be presented by DFS personnel to other jurisdictions willing to cover costs. Contact 
Montgomery County, Department of Facilities and Services, Capital Projects Management Division, Senior Energy Engineer, for information.

\section{RESULTS}

The agencies receiving transfer of the Guidelines provided on-going feedback on the process successes and difficulties. The general results were as follows:

- Each agency was successful in using substantial parts of the Guidelines immediately on new building design. The existing staff of engineers and architects were able to implement the Guidelines and control the design process after receiving training as described in this chapter.

- In the area of lighting, all agencies adopted the recommended parabolic, electronic 78 fixtures for new design. The Public Schools chose to limit installed wattage to 100 percent of the wattage allowed by the ASHRAE 90.1 standard, rather than the more conservative 65 percent recommended by the Guidelines. The other agencies used 65 percent.

- In the area of IAQ/Ventilation, the Public Schools elected to use existing codes rather than the ASHRAE Standard 62 recommended by the Guidelines. The high occupant density in schools would lead to much larger ventilation of schools under Standard 62. The control and energy implications of Standard 62 may need further development for schools.

- Adoption of Thermal Envelope improvements received little resistance, with most consultants agreeing that BOCA minimum insulation standards were far too low to even provide a comfortable building for occupants. 
- The agencies were able to adopt the Guidelines without intervention from higher-level management. The Guidelines were introduced as a revision of engineering standards using existing authority to set standards.

Following are some examples of buildings designed under the transferred Guidelines:

- Montgomery Community College designed a $\$ 10,000,000$ Institute for Technical Education with classrooms and laboratories featuring lighting below $1.2 \mathrm{~W} / \mathrm{ft} 2$, daylight dimming, low-emissivity glazing, and a natural gas engine to drive a chiller and co-generate heat.

- Montgomery County Public Schools designed Germantown Middle School featuring lighting design of $1.5 \mathrm{~W} / \mathrm{ft2}$, an energy-efficient envelope exceeding ASHRAE standard 90.1-1989 requirements and using lowemissivity insulating glass, unit ventilators with full economizer operation, and a central ice storage system to reduce cooling power peak demand by 50 percent.

Projected energy consumption in these buildings is 50 percent lower than the existing facilities in both agencies. Both were designed within the original construction budget for the building type based on conventional square foot estimates. 


\title{
Chapter 5 - Lessons for Application
}

\author{
LESSONS LEARNED
}

The five most important lessons to emerge from this transfer project are the following:

* Iransfer Need Not Be Difficult: Other jurisdictions can readily adopt Energy Design Guidelines and produce significantly better buildings without increasing construction costs. Transfer to three other agencies went smoothly using their in-house staff. The agencies are designing more efficient buildings than would otherwise have been achieved. A "bottom-up" approach was used whereby the agencies introduced the Guidelines under existing lower-level authority to set engineering standards for building design.

* Provide Training to In-House Staff: Using the Guidelines successfully requires training of in-house personnel for project management and technical reviews. This requirement was not a major obstacle if the agency had existing staff with professional architectural or 'engineering background. Over the course of this project, three days time was spent on training.

* A Comprehensive Approach is Needed: Transfer of the Guidelines went smoothly because the concepts were introduced into the project's initial planning. For best results, the design process should be adopted in its entirety before the start of a new project. A smooth design process depends on selecting a design team with appropriate expertise and using a design contract with all provisions needed to implement the technical Guidelines. 
Schematic Design is Too Late to Enter the Process: Conventional wisdom is that energy conservation must begin at Schematic Design. In practice we find that energy conservation planning must begin long before that point. In some past designs by DFS the Guidelines were introduced during design and encountered considerable resistance from the designers and project managers. Energy must be integrated into the program of requirements and properly budgeted, especially for renovations, prior to even issuing a request for proposals on design. To enter as late as Schematic Design is to invite disruption and delay.

* Enerar Design Guidelines are Highly Cost-Effective: The transfer project confirmed that other agencies could implement the Guidelines with similar staff levels used by DFS. In previous (YR 9) research, the cost of the Energy Design Guidelines program instituted by DFS was found to be small relative to the avoided utility costs resulting from this effort. The Benefit-to-Cost ratio of 8 to 1 exceeds that of a well run energy retrofit program.

SUGGESTIONS FOR APPLICATION

The economics of energy-efficient design are very favorable and should be attractive to local governments. Yet very few local governments have energy design improvement programs, even though they have aggressive energy retrofit programs. It is apparently a case of the one hand not knowing what the other one is doing; buildings are designed to old standards while retrofit programs are upgrading them to new standards. The reason for this discrepancy is not entirely clear but may have to do with lack of information and also the difficulty of coordination involved. Our suggestion to other jurisdictions seeking to transfer our results would be as follows:

\section{Study Your Facility Development Process}

The Energy Manager should first have a comprehensive view of the facility planning, development, design and construction process in their jurisdiction. Find out when and how projects are defined and budgeted. Find out who is 
responsible for design and who has access to perform reviews and make comments during programming and design.

Obtain Permission to Introduce Energy Design Guidelines: Establish who can introduce energy requirements into the process and obtain consent to beg in a program of energy design requirements. If you are an insider to the design process, this step may be simple or even up to you to decide. If you have the authority to set engineering standards for your bulldings then you may be able to introduce the Guidelines as revised standards. If you are an outsider to the design process of your facilities, more selling may be needed. The video produced as part of this transfer project can help in selling the idea. Typical objections and myths you may meet and appropriate responses are as follows:

Objection or Myth: Energy Conservation is Unaffordable.

Answer: Energy Guidel ines Tend to Lower First-Cost, Not Increase It. In most cases, first-cost can be held the same or even reduced while cutting building energy consumption by 30 to 50 percent. If utility rebates are available in your area, you should be able to show a positive cash flow into the project from energy conservation measures.

Objection or Myth: Energy Conservation Means Deprivation.

Answer: Construction Quality and Occupant Comfort will be Improved by Energy Guidelines. Energy efficiency does not mean "freezing in the dark". It means doing a better job with less energy waste. An efficient building will feature high-quality glare-free lighting, advanced temperature controls, and a thermal envelope that eliminates cold spots and drafts in the winter, and reduces solar glare and overheating in the summer. Comfort, quality and efficiency go hand-in-hand in a well organized design process.

Objection or Myth: Energy Codes and Normal Design are Already Good Enough. Answer: $\quad$ Substantial. Permanent Savings Can Be Achieved over Current Codes. Energy use in buildings built to Guidelines can be 30 to 50 percent lower than normal design practice produces. The savings in annual operating costs are significant. Built-in 
efficiency can generally be expected to last the life of the building, over 50 years for most commercial buildings. More design effort and review effort is required, but the cost of this effort is dwarfed by even the first year of utility savings on most projects.

Receive and Adapt DFS Guidelines and Contract Provisions

The materials you need to start a program are available from the Urban Consortium. Key components are as follows:

- Energr Design Guidelines, a comprehensive notebook of standards, technologies, design approaches and specifications you need to design an efficient building.

- Design contract provisions needed to implement the Guidelines.

- Detailed formats for the energy reports to be generated at Schematic Design and Design Development.

- Selection criteria for designers when you issue a Request for Proposals on design of new building.

\section{Establish a Formal Coordination Process on Energy Requirements}

To keep a project on track will require coordination points all along the process. Government project managers must check compliance at these points. obtain a requirement for signature on passing a coordination point if possible.

Each coordination point should have well-defined products for review by the government energy manager. Particularly in energy reports, tachnical coverage and documentation should be carefully specified and enforced. Our flow chart containad in the Guidelines Overview section describes the checkpoints we have established in our process. Adaptation to the local process is necessary. Our energy report requirements describe specific technical coverage requirements for energy design.

Remember to View the Building as a whole.

When reviewing plans and discussing costs, remember to think of energy-conscious design as an architectural, mechanical, and electrical integration exercise, not an "add-on" issue. The energy analysis tool used should be comprehensive in treating all these elements together. In this way important cost trade-offs can be made between systems. Often, no-cost 
decisions can be made which decrease energy use. When buildings are viewed as a whole, experience shows that energy-efficient construction need not cost any more than standard construction.

FUTURE DIRECTIONS

Montgomery County maintains the willingness and expertise to assist other jurisdictions with energy-efficient design of their buildings. Seminars and training can be arranged on a fee basis through our "Energy-Efficiency Design Center". Contact Montgomery County, Department of Facilities and Services, Senior Energy Engineer, for more information. 


\section{Report and Information Sources}

Additional copies of this report "Energy-Efficient Bullding Design - A Transfer Guide for Local Governments", are available from:

Publications and Distribution

Public Technology, Inc.

1301 Pennsylvania Avenue, NW

Washington D.C. 20004

For additional information on the methods, results and uses of the information contained in this report, or for information on other energy management activities in Montgomery County, Maryland, please contact:

Ronald J. Balon, P.E.

Senior Energy Engineer

Capital Projects Management Division

$110 \mathrm{~N}$. Washington Street, 3rd floor

Rockville, Maryland 20850

(301) 217-6091

DG $/ 91-317$

02/93-150 


\section{Publications Price List--UCETF Reports}

TITLE

PRICE

15.00

ITEM

Hydraulic Waste Energy Recovery: A Technical Report

$90-318$

A Regulatory Framework for Alternative Fuels and Transportation Management Services

15.00

$90-316$ Alternative Vehicle Fuels: A Demonstration Project

15.00

$90-314$

Energy Efficiency in Public Housing

15.00

89.330

Analysis of Programmatic Fleet Conversion to Ethanol Blends

15.00

$89-325$

An Alternativ Fuels Evaluation System for Fleet Vehicles

15.00

$89-32$

Dual Fuel Conversion Deinonstration and Technology Transfer Project

10.00

89.321

Summary of Low and Moderate Income Residential Energy Conservation Programs

15.00

89-315 A Case Study in the Pursuit of Urban Energy Efficiency

15.00

89-31

Communicating with the Public About Environmental Health Risks: A Case Study

13.00

89-313 Evaluation and Comparison of Selected Household Hazardous Waste Collection Facilities

15.00

89-311 Yard Waste Recycling Study: A Pilot Study

15.00

$89-310$

Sludge Storage Lagoon Biogas Recovery and Use, Volume 1

15.00

$89-307$

Proceeding: 1989 Electric Utility Franchise Conference

20.00

89-306 Reducing Electricity Demand Through Energy-Related Efficient Construction

15.00

$89-304$

Modernization of Lighting in Municipal Auditoriums

15.00

89-303 Wastewater Treatment Process Energy Optimization

13.00

89-301 Implementation of Alternative Technologies through the Assessment of Energy Markets

14.00

$88-322$ Marketing Energy Efficiency Programs to Commercial and Industrial Firms: Lighting Incentives and

14.00

$88-32$

Urban Energy Management Today: Ten Year Compendium of UCETF Programs

15.00

$88-31$ Integrating Energy Efficiency Into Municipal Purchasing Decisions: Computerizing Procurement

10.00

$88-318$

Household Hazardous Waste: Implementation of a Permanent Collection Facility

15.00

$88-317$

Hazardous Waste as an Energy Manager's Issue

20.00

88.317

88-316 Household Hazardous Waste Management Planning

15.00

15.00

88-312

$88-310$

Summary of Small Business Energy Conservation Programs

15.00

$88-309$

The Earth-Coupled Heat Pump: Utilizing Innovative Technology in Single Family Rehabilitation

15.00

Energy Planning for Economic Development

18.00

88.308 Conversion of Resource Recovery Steam to Hot and Chilled Water Systems

10.00

$88-306$

HVAC Equipment Replacement for Best Size and Efficiency, Transfer Report

15.00

88-305 Cogeneration and Cooling in Small Scale Applications

15.00

$88-304$

22.00

$88-303$

88-302

Energy Master Planning: Innovative Design and Energy Analysis Services for New Commercial

15.00

Energy Efficient Building Design: Guidelines for Local Government

15.00

$88-301$

87.327 Direct Digital Control of Air Washer Cooling System

18.00

Feasibility Study of Transportation Management Strategies in the Poplar Corridor, Memphis, Tennessee

20.00

87.324 Energy Effiicient Urban Cooling Technologies: 1st National Gonf.

15.00

$87-317$ Memphis Area Rideshare 15.00

$87-314$ Joint City Government/Utility Partrerships to Reduce Business Costs 


\section{Publicalions Price List--UCETF Reports}

87-310 Hidden Link: The Energy and Economic Development, Phase II

87-307 Municipal Underground Storage Tanks: An Energy Manager's Guide

87-306 Intergrating Energy Efficiency into Mun. Purchasing Decisions 20.00

87-305 Energy Enhancement in New Residential Construction 40.00

87-302 Thermal Energy Storage: Application Guide for Local Governments 20.00

87-301 HVAC Equipment Replacement for Best Size \& Efficiency 20.00

86-315 Balancing Single Pipe Steam Heating Sytems 20.00

86-314 Inhibition of Respiration in Activated Sludge by High Carbon Dioxide Concentration 7.50

86-313 Water Supply System Energy Conservation Through Computer Control 18.00

86-312 Energy Cost Reduction Through Wastewater Flow Equalization 20.00

86-311 High Efficiency Gas Furnace Modification in Low Income Housing 15.00

86-310 Hidden Link: Energy and Economic Development, Phase I 15.00

86-307 Disposal Techniques wilh Energy Recovery for Scrapped Vehicle Tires 20.00

86-306 District Heating Marketing: Analysis of a Twelve City Survey 20.00

86-305 Technology Transfer for Residential Energy Programs in New Construction and Existing Housing 15.00

86-304 Technology Transfer for Residential Energy Efficiency 15.00

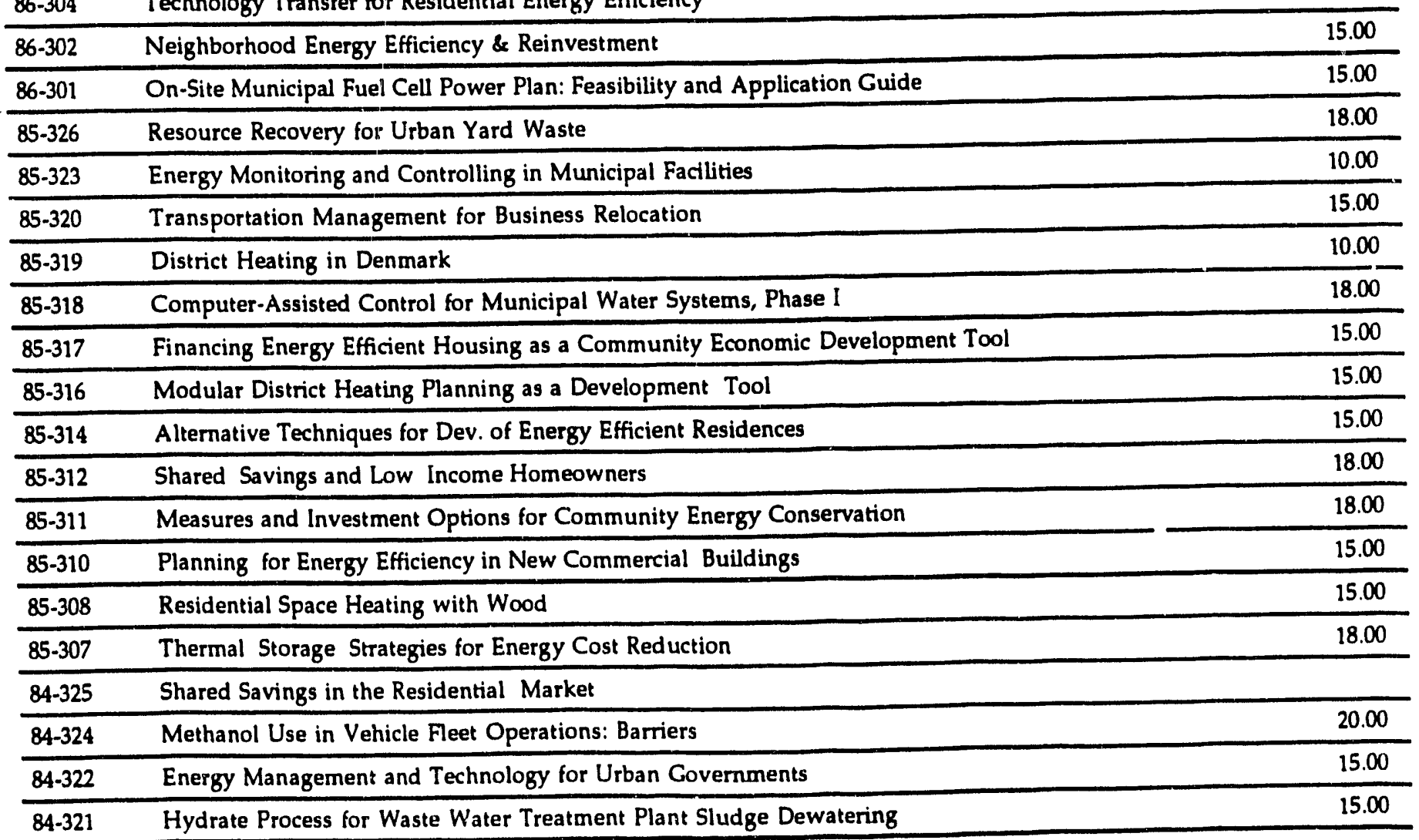




$314 \quad$ Application of Mini-Van Technology to Vanpool Services 18.00

312 Implementation Methods for an Integrated Energy System 10.00

$311 \quad$ Feasibility of Water-Based District Heating and Cooling 15.00

$310 \quad$ Budgetary Incentives for Municipal Energy Management 22.00

$309 \quad$ Central Energy Systems Applications to Economic Development 20.00

$308 \quad$ On-Site Cogeneration for Office Buildings 15.00

$306 \quad$ Analysis of Municipal Bus Operations for the Advancement of Fuel Cell Technology 15.00

$305 \quad$ Computer Based Maintenance 15.00

$304 \quad$ Innovative Finance Plans for Privately Owned Waste/Vol. 2

$303 \quad$ Innovative Finance Plans for Privately Owned Waste/ Voi. 1

$301 \quad$ Coordinating Preventive Maintenance with Energy Management 15.00

319 The Rehabilitation and Retrofit of Older Houses to Superinsulated Standards 15.00

-318 Developing Sources and Techniques for Alternative Financing of Energy Conservation 20.00

$-316 \quad$ Hydrate Process for Dewatering Sewage Sludge 10.00

$-315 \quad$ Financial Planning for District Heating: Brooklyn Navy Yard 15.00

$-314 \quad$ Memphis Area Rideshare On-Line Information System 18.00

$-313 \quad$ Renovation Opportunities for Steam District Heating Systems 18.00

-312 Initial Assessment of District Heating and Cooling 20.00

-311 Energy Conservation Through Computerized Automation 18.00

-309 Development of an Energy Park: Issues and Implementation Options 15.00

-308 Alternative Uses for Digester Methane Gas 25.00

$-307 \quad$ Innovative Financinz and Incentive Package to Reduce Energy 15.00

-305 Multi-jurisdictional Planning for District Heating and Cooling 10.00

- $303 \quad$ Improving Energy Management and Accountability in Municipal Operations 15.00

-320 Utilization of Felled City Trees as Supplemental Boiler Fuel 7.50

-319 Methanol Use in Vehicle Fleet Operations: Comparisons 15.00

$-317 \quad$ Microcompter Tools for Trans. and Residential Energy Conservation 20.00

,-316 Reduction of Impediments to Alternative Energy Use 20.00

, $.315 \quad$ Reducing Regulatory and Financial Iḿpediments to Energy Conservation 20.00

,-314 Integrating Energy Management with Economic Development 20.00

Energy Conservation and Economic Development 10.00

i.310 Municipal Technologies 20.00

J-307 Strategies to Improve Community Energy Use Practices 10.00

3.306 Energy Conservation In Water Treatment

2-305 Development of an Energy Action Plan: Participating Approach 15.00

2-303 Energy Economic Development 20.00


Publications Price List-UCETF Reports

ITEM \#

TITLE

PRICE

82. 302 Public Housing Energy Efficiency Through Private Financing

10.00

82-300 Developing an Energy Management Tracking System

\begin{tabular}{lll}
\hline $81-328$ & Matching End Use Energy Needs to Source Possibilities & 20.00 \\
\hline $81-327$ & Development of a Hydrogen-Fueled Mass Transit Vehicle s & 15.00 \\
\hline
\end{tabular}

81-326 Operational and Maintenance Guidelines for Reducing Energy Consumption

81-324 Energy Management for Small Business 10.00

\begin{tabular}{lll}
\hline $81-320$ & Energy Data Gathering, Analysis, and Review System & 20.00 \\
\hline $81-318$ & Fuel Management and Planning System for Local Covernment & 25.00
\end{tabular}

81-316 Prosuction of Ethanol from Cellulosic Fraction

81-313 Metro-Dade County Comprehensive Enerpy Emergency Plan 15.00

$81-311 \quad$ Developing Energy Emergency Prepardross 15.00

\begin{tabular}{llll}
$81-310$ & Simplified Methodology for Community Energy Maniagemerit & 20.00 \\
\hline $81-309$ & Energy Management: The Public Sector & 15.00
\end{tabular}

\begin{tabular}{ll} 
81-309 Energy Management: The Public Sector \\
\hline $81-307$ & Municipal Technical Assistance-Energy Monitoring
\end{tabular}

81-306 New Technology Demonstration 10.00

81-305 Technology Transfer: Unit Report from the Energy Task Force 15.00

81-304 Development of Local Energy Management Preparf:dness 10.00

81-303 Municipal Energy Management 10.00

\begin{tabular}{llll}
\hline $80-314$ & Methodology for Energy Impact Analysis of Urban Development Projects & 15.00 \\
\hline $80-313$ & Evaluation of Landfill Gas as an Energy Source & 15.00 \\
\hline $80-309$ & Decision Process for the Retrofit of Municipal Buildings & 20.00 \\
\hline $80-308$ & Primary Urban Energy Management Planning Methodology & 7.50 \\
\hline $80-306$ & Local Government Use of Thermography for Energy & 15.00 \\
\hline $79-300$ & Planning for and Purchasing Computer Technology & 6.50 \\
\hline
\end{tabular}


$\nabla$
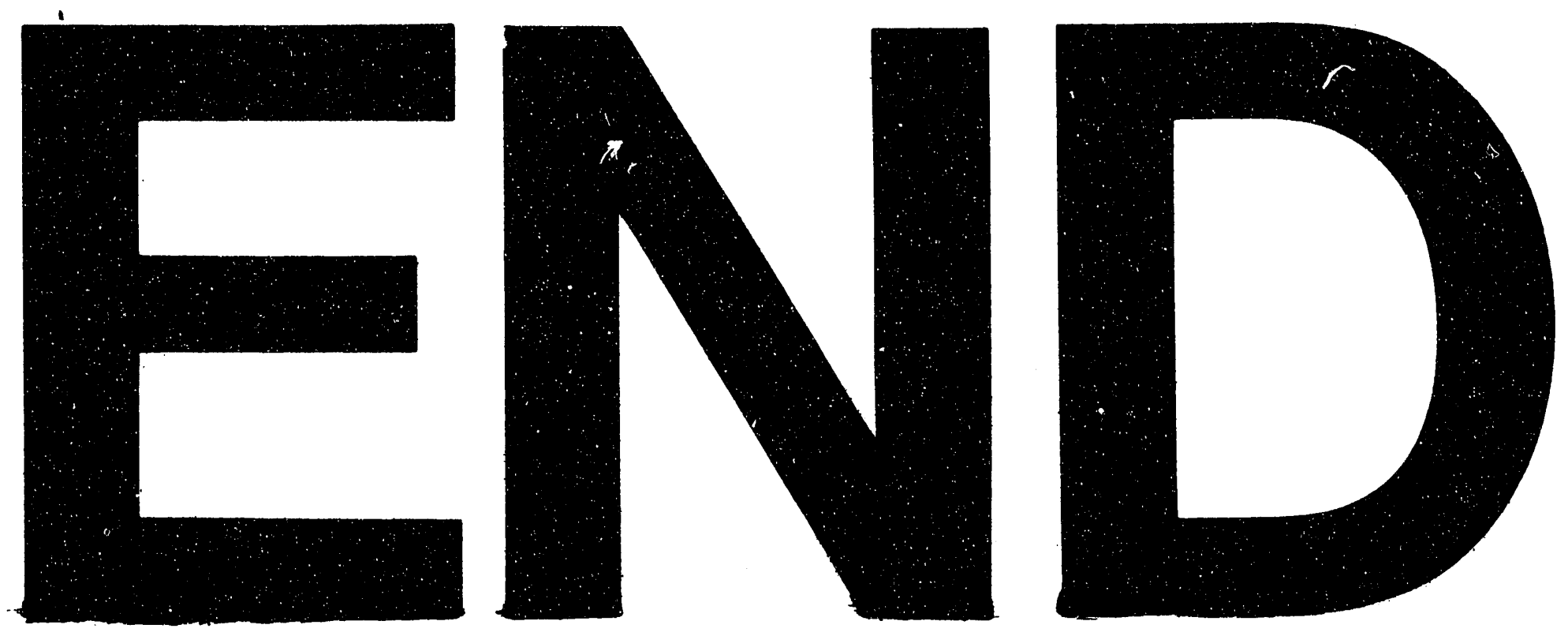

Fis

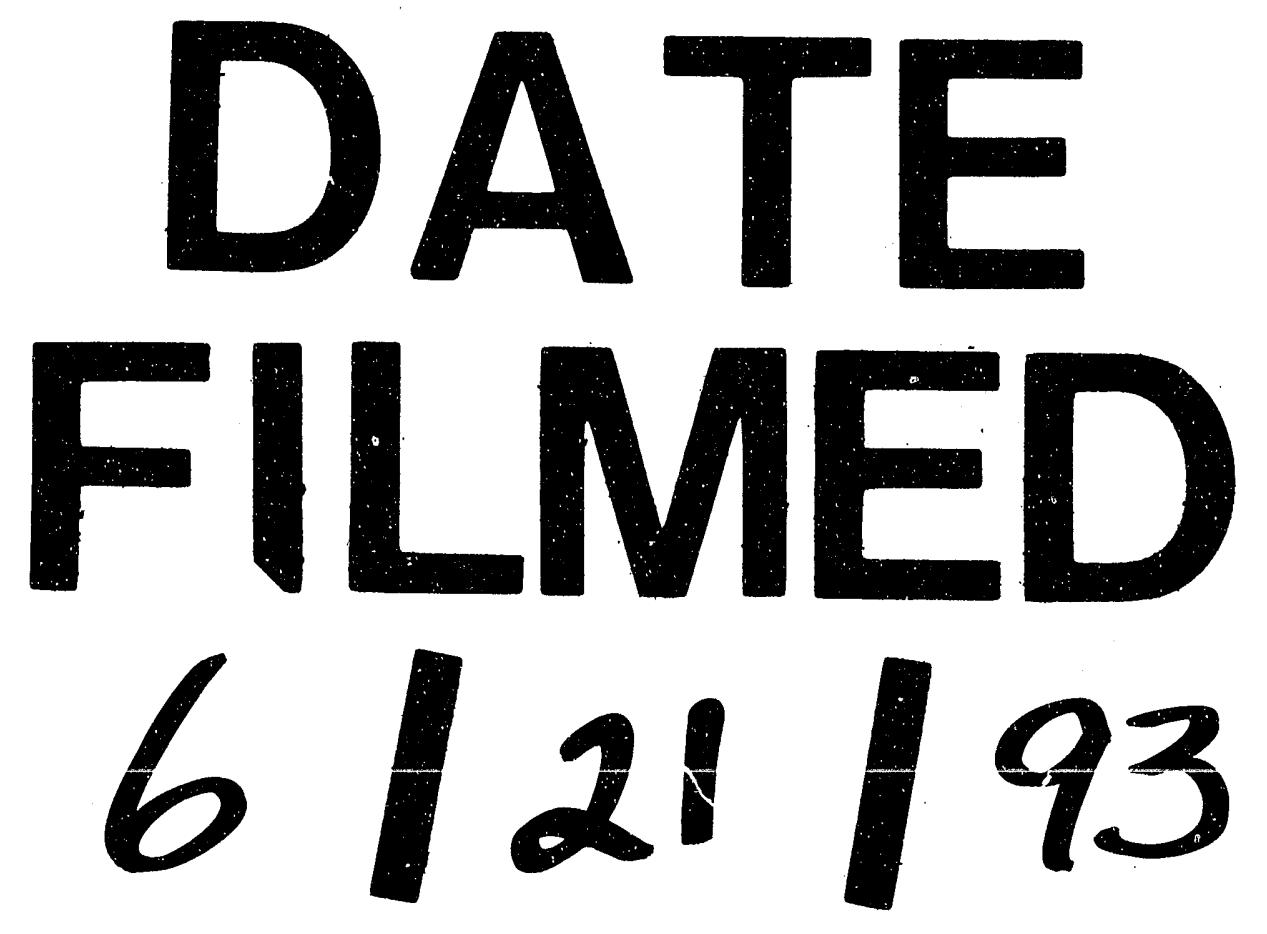


$\mid$ 